PPPL--2631

DE89 014598

\title{
Multiple Mode Model of Tokamak Transport
}

\author{
C. E. Singer, E-S. Gharem \\ University of Illinois at Urbana-Champaign \\ G. Bateman, and D. P. Stotler \\ Princeton Plasma Physics Laboratory \\ Princeton University
}

Theoretical models for radial transport of energy and particles in tokamaks due to drift waves, rippling modes, and resistive ballooning modes have been combined in a predictive transport code. The resulting unified model has been used to simulate low confinement mode (L-mode) energy confinement scalings. Dependence of global energy confinement on electron density for the resulting model is also described.

\section{DISCLAIMER}

This report was prepared as an accounl of work sponsored by an agency of the United States Government. Neither the United States Government nor any agency thereof, nor any of their employees, makes any warranty, express or implied, or assumes any legal liability or responsibility for the accuracy, completeness, or usefulness of any information, apparaltss, product, or process disclosed, or represents that its use would not infringe privately owned rights. Reference herein to any specific commerciul product, process, or service by trade name, trademark, manufacturer, or ofherwise does not necessarily constitute or imply its endorsement, recommendation, or favoring by the United Stales Government or any agency thereof. The views and opinions of authors expressed berein do not necessarily state or reflect those of the United States Government or any agency thereof. 


\section{Introduction}

A major goal of controlled fusion research is to obtain a theoretical description of plasma transport across the toroidal magnetic flux surfaces in tokamaks. Computational models which could predict the evolution of fluxsurface-averaged plasma parameters in new experiments would be particularly useful. A number of previous computational studies of turbulent plasma transport bave concentrated individually on various features of the drift-wave $[1,2]$ or resistive ballooning modes $[3]$. These simulations have been successful in reproducing some features of low-confinement (L-mode) plasmas. However, computational models based on drift-wave theories alone are reportedls inadequate to reproduce scaling of global energy confinement with toroidal plasma current [4]. A model containing fluxes due to resistive ballooning modes reproduced some data from the Impurity Study Experiment (ISX-B) [3] but was not subsequently shown to reproduce results from other tokamaks.

In the present study, we use linear combinations of theoretical transport fluxes due to drift waves, resistive ballooning, and rippling modes, added to a fixed level of neoclassical transport. Such models are used to study the scaling of global energy confinement with various plasma parameters in L-mode plasmas. The original motivation for our simulations is based ou comments in papers by $\mathrm{T}$. Hahm, P. Diamond, and colleagues $[5,6]$. The rationale for the transport formulas used and a qualitative discussion of the expected results is given elsewhere [7]. An approximate analytic integration and the motivation for one of the levels of rippling mode fluxes used here was presented by Sheffield [8].

\section{Transport Model}

To the usual neoclassical fluxes $[9-11]$, we added a linear combination of estimates of drift-wave, rippling mode, and resistive ballooning effects $[4,6,7,12-18]$.

$$
Q_{i, e}=c_{1} Q_{i, e}^{D R}+c_{2} Q_{i, e}^{R M}+c_{3} Q_{i, e}^{R B}
$$

for ion (i) and electron energy fluxes and $\Gamma_{a}=c_{1} \Gamma_{a}^{D R}+c_{2} \Gamma_{a}^{R M}$ for the flux of each hydrogen isotope, $a$.

For drift waves, the approximation $\Gamma_{a}^{D R}=c_{1} D^{D R_{n_{a}} / L_{n}}$ was used for 
flux-surface-averaged quasilinear radial particle fluxes. Here

$$
D^{D R}=\frac{1+\beta^{\prime} / \beta_{c 1}^{\prime}}{1+\left(\beta^{\prime} / \beta_{c 1}^{\prime}\right)^{3}}\left(1-\frac{f_{i t h}}{.95+\nu_{e}^{*}}\right) \dot{D}_{t e}
$$

with $\beta^{\prime}=-d \beta / d r$ and $\beta_{c 1}^{\prime}=\dot{s} /\left(1.7 q^{2} R_{0}\right)$. The corresponding heat fluxes are

$$
\begin{aligned}
& Q_{e}^{D R}=\left(\frac{5}{2}-\frac{3}{2} f_{i t h}\right) \frac{1+\beta^{\prime} / \beta_{c 1}^{\prime}}{1+\left(\beta^{\prime} / \beta_{c 1}^{\prime}\right)^{3}} \hat{D}_{t e} \frac{n_{e} T_{e}}{L_{T_{e}}} \\
& Q_{i}^{D R}=\frac{5}{2}\left(\hat{D}_{t e}+f_{i t h} \hat{D}_{i}\right) \frac{1+\beta^{\prime} / \beta_{c 1}^{\prime}}{1+\left(\beta^{\prime} / \beta_{c 1}^{\prime}\right)^{3}} \frac{n_{i} T_{i}}{L_{T_{i}}}
\end{aligned}
$$

For completeness, the small anomalous electron $\rightarrow$ ion energy exchange

$$
\Delta^{D R}=c_{1}\left(0.89-0.54 \eta_{i}-0.6 \beta^{\prime} / \beta_{c 1}^{\prime}\right) D^{D R} \frac{n_{e} T_{e}}{L_{n}^{2}}
$$

was also included $[14,19]$. In these formulas we use the notation adopted by Ross et al. [15] from the work of Dominguez and Waltz [4], with

$$
\begin{aligned}
& \hat{D}_{t e}=\epsilon^{1 / 2} \frac{\omega_{e}^{*}}{k_{\perp}^{2}}\left[1, \frac{\omega_{e}^{*}}{\nu_{e} f f}\right]_{\min } \\
& \hat{D}_{i}=\frac{\omega_{e}^{*}}{k_{\perp}^{2}}\left(\frac{2 T_{i}}{T_{e}} \frac{L_{n}}{L_{T_{i}}} \frac{L_{n}}{R_{0}}\right)^{1 / 2}
\end{aligned}
$$

Here $f_{i t h}=\left\{1+\exp \left[-6\left(\eta_{i}-\eta_{i}^{t h}\right)\right]\right\}^{-1}, \eta_{i}^{t h}=1$ for $L_{n} / R_{0} \leq 0.2$ and $\eta_{i}^{t h}=$ $\left(0.5+2.5 L_{n} / R_{0}\right)$ for $L_{n} / R_{0}>0.2$.

The rippling mode fluxes are $\Gamma_{a}^{R M}=D_{\nabla \eta} n_{a} / L_{n}, Q_{e}^{R M}=D_{\nabla_{\eta}} n_{e} T_{c} / L_{n}$, and $Q_{i}^{R M}=D_{\nabla \eta} n_{i} T_{i} / L_{n}$ with

$$
D_{\nabla_{\eta}}=\left(\frac{E_{0} L_{s}}{B_{0} L_{\sigma}}\right)^{4 / 3}\left(\frac{r^{2} L_{s}^{2} Z_{i m p}^{2} \nu_{i i}}{25 v_{i}^{2}}\right)^{1 / 3}
$$

The resistive ballooning theory used affects only electron energy fluxes:

$$
Q_{e}^{A B}=\Lambda_{S}^{2} \chi_{e, \text { res.ball }} \frac{n_{e} T_{e}}{L_{T_{e}}}
$$


where

$$
\chi_{\text {e.res.ball }}=\frac{3 v_{e} \eta}{2 \mu_{0}(2 q)^{1 / 2} v_{A}}\left(\frac{\beta_{\theta} \epsilon^{2} L_{s}}{L_{p}}\right)^{3 / 2}
$$

and

$$
\Lambda_{S}=\frac{4}{3 \pi} \ln \left(\beta^{-1 / 2} R_{0} v_{A} \mu_{0} / \eta\right)
$$

from Diamond and Carreras $[17,18]$.

Except for the leading coefficients $\left(c_{1}, c_{2}\right.$, and $\left.c_{3}\right)$, the symbols in these expressions are defined in Table 1 . Here $r$ is the midplane half-width of a flux surface, $R_{0}$ is the major radius, $\epsilon=r / R_{0}, B_{0}$ is the toroidal magnetic field, $Z_{\text {imp }}=6$, and $E_{0}$ and $q$ are the local toroidal electric field and safety factor computed from the time evolution of the poloidal and toroidal fluxes. The fundamental physical constants in these formulas are $\mu_{0}=4 \pi \times 10^{-7}$, $\epsilon_{o}=8.8542 \times 10^{-12}, c=\left(\mu_{o} \epsilon_{o}\right)^{-1 / 2}, e=1.6022 \times 10^{-19}, m_{e}=9.1095 \times 10^{-31}$, $m_{p}=1.6726 \times 10^{-27}$, and $k_{b}=1000$ e. (In this paper we use SI units except that temperatures are in $\mathrm{keV}$ and heat fluxes are in $\mathrm{keV} \cdot \mathrm{m}^{-2} \mathrm{~s}^{-1}$.)

For numerical convenience, the scale lengths in the above formulas are limited to a physically reasonable minimum: $\left|L_{X}\right| \geq \rho_{\theta i}$ (for $X=n, T_{e}, T_{i}$, or $p$ ). The shear is limited to $\hat{s}<r / \rho_{\theta i}$ when (and only when) using it for computing the above turbulent transport flux formulas. Also, the analytic approximation given above for the ideal ballooning limit, $\beta_{c l}^{\prime}$, breaks down, for example, when $\hat{s} \overline{<}-\sigma^{\prime}$, where $\sigma^{\prime}$ is the radjal derivative of the Shafranov shift [20]. As a result of these considerations, the shear is also limited to a minimum $0.5<\hat{s}$ when (and only when) using it for computing the above turbulent transport flux formulas. This also helps keep the rippling mode fluxes from becoming too large in regions of very low shear.

The total transport flux formulas are thus defined when the leading coefficients $c_{1}, c_{2}$, and $c_{3}$ are given. Here we treat the nominal predictions of the theories, $c_{1}=c_{2}=c_{3}=1$, as rough estimates and allow some of these coefficients to vary over an order of magnitude range centered on 1 .

\section{Results}

Here we report some quantitative simulation results which illustrate that the type of model described above can reproduce important features of neutral-beam-heated plasmas. The first results given here are L-mode global 
confinement scaling exponents $\left(\partial \ln \tau_{E} / \partial \ln X\right)$ where $X$ is either the toroidal plasma current, $I$, the toroidal magnetic field, $B$, the neutral beam heating power, $P$, or the line average density, $\bar{n}_{e}$. These results were obtained using the approximation $\left(\partial \ln \tau_{E} / \partial \ln X\right) \sim\left[\left(\tau_{1}-\tau_{2}\right)\left(X_{1}+X_{2}\right)\right] /\left[\left(\tau_{1}+\tau_{2}\right)\left(X_{1}-X_{2}\right)\right]$ where $\tau_{1}$ is the global thermal kinetic energy confinement time computed for a reference point $\left\{X_{1}\right\}=\left(3.75 \times 10^{5}\right.$ Ampere, 2.2 Tesla, $2.3 \times 10^{6}$ Watt, $\left.4.0 \times 10^{19} \mathrm{~m}^{-3}\right)$, and $\tau_{2}$ is computed for each value of $X$ separately reduced by $20 \%$. The remaining parameters, including the neutral beam configuration and the plasma current and density ramp forms, were set equal to the Axisymmetric Divertor Experiment (ASDEX) parameters given by Singer et al. [11] with the limiter-plasma boundary conditions given by Singer, Bateman, and Stotler [21].

The results are listed in Table 2 for a "nominal" model [with drift, rippling, and resistive ballooning coefficients, respectively $\left.\left(c_{1}=c_{2}=c_{3}=1\right)\right]$ and an "improved" model in which the coefficient of the drift contribution was reduced to 0.3 and the coefficient of the rippling contribution was increased to 3 (i.e., $c_{1}=0.3, c_{2}=3$, and $c_{3}=1$ ). The choice of $c_{2}=3$ rippling mode coefficient in the "improved" model was motivated by the studies of Sheffield [8]. The coefficient $c_{1}$ was then adjusted to give a reasonable fit to observed plasma profiles and L-mode confinement scalings inferred from fitting a large data base. The first two columns in Table 2 show the scal. ing exponents for current $(I)$, magnetic field $(B)$, auxiliary heating $(P)$, and density $\left(\vec{n}_{e}\right)$ from our simulations ("nominal" and "improved," respectively.) The other numbers listed in Table 2 are experimental scaling exponents deduced by Singer [22], Kaye and Goldston( "K-G" [23]) and updated exponents obtained by Kaye using a larger data base [24]. (The confinement scalings from Kaye [24] used the "all" of the data base which was available and a two-step, "complex" method of computing confinement scalings for each device and then averaging the confinement scalings. The scaling exponents obtained from other methods of reducing the same data were very similar to the resulting "Kaye-All-Complex" exponents shown in Table 2. The global energy confinement time computed for the reference discharge from this scaling was 0.026 seconds, compared to 0.028 seconds for the simulation with the "improved" transport model.)

It is apparent from Table 2 that the L-mode scalings from the "improved" model are compatible with those inferred from experiment within the vari- 
ation of the results obtained by analyzing different data bases. The figures in bold type show a good correspondence of the best model analyzed so far with the confinement scaling derived from the most complete data base.

Without further adjustment of the transport fluxes, the "improved" theorybased model just described was also used to simulate ohmically heated plasmas. A curve showing simulated confinement times as a function of line average density is compared to experimental data points in Fig. 1. The simulations used to produce the curve in Fig. 1 are identical to the ohmic phase of the discharge using the "improved" model described above, except that the plasma current was changed from 0.375 MA to the 0.4 MA used for the experimental data given above [25]. Although the magnitude of the transport coefficients has not been adjusted to match the ohmic confinement data, the model evidently predicts an initial rise and eventual saturation of confinement with increasing line average density.

\section{Conclusions}

The results shown here indicate that theoretical transport models based on local plasma parameters can be used to describe important qualitative features of plasma transport across closed flux surfaces in tokamaks. Such results had not previously been successfully obtained in computational transport simulations using fluxes for individual modes. Since theory predicts that all of these modes may be simultaneously important somewhere in a given plasma, it is not surprising that each mode would not work adequately alone in predictive simulations. The "improved" model described above also gives reasonably accurate electron temperature and density profile shapes both for the limiter plasmas simulated here and for the high confinement in divertor discharges when models of the shear [7] and the evolution of the boundary temperature [21] are included. This suggests that a systematic survey would be worthwhile to determine the ranges of unknown parameters in these models allowed by existing experimental data. A systematic statistical methodology for conducting such a survey has been worked out in detail and described elsewhere [26]. An estimate of the computational requirements suggests that it would be practical to vary the three adjustable parameters in the present model $\left(c_{1}, c_{2}\right.$, and $\left.c_{3}\right)$ when treating a data base consisting of tens of discharges. 
However, it should be kept in mind that, for example, the quasilinear saturation levels for transport due to drift waves would in reality be expected to be a slowly varying function of relevant dimensionless plasma parameters; i.e., $c_{1}=c_{1}\left(q, \nu_{e}^{*}, \rho_{i} / L_{p}, \ldots\right)$. Even allowing only simple power law variations for such dependencies would introduce a large number of additional free parameters. There are also additional theoretical uncertainties in the present formulation of drift-wave and other turbulent transport models. Treating a large number of adjustable parameters would either require a much more efficient computational model or the use of some simplified description of the model's response to variation of the adjustable parameters.

Another difficulty is that both the theory and the available data base evolve faster than an aggressive experimental simulation program can be carried out. For this reason, we have frozen the theory at a relatively simple level and used only a very rough description of the available data in the present work. Despite all of these difficulties, we believe the results presented here illustrate a useful starting point for calibrating improving theoretical tokamak plasma transport models against an expanding empirical data base.

\section{Acknowledgments}

The authors acknowledge conversations with $G$. Rewoldt and support from Princeton Plasma Physics Laboratory subcontract S-03004-B and U. S. Department of Energy Contracts DE-FG02-88ER53269 and DE-AC02-76CH03073. 


\section{References}

[1] M. H. Redi, W. M. Tang, P. C. Efthimion, D. R. Mikkelsen, and G. L. Schmidt, "Transp ort Simulations of TFTR Using Microinstability Based Profile Consistent Models for Electron and Ion Thermal Transport," Nucl. Fusion 27 (1987) 2001.

[2] D. W. Ross, W. H. Miner, Jr., P. M. Valanju, and J. C. Wiley, "Transport Sirnulation with Theoretically Based Models," Bull. Am. Phys. Soc. 33 (1988) 2028.

[3] B. A. Carreras, P. H. Diamond, M. Murakami, J. L. Dunlap, J. D. Bell, H. R. Hicks, et al., Phys. Rev. Lett. 50 (1983) 503.

[4] R. Dominguez and R. E. Waltz, Nucl. Fusion 27 (1987) 65.

[5] P. Diamond, University of Texas Institute for Fusion Studies (private communication, 1987).

[6] T. S. Hahm, P. H. Diamond, P. W. Terry, L. Garcia, and B. Carreras, Phys. Fluids 30 (1987) 1452 .

[7] C. E. Singer, "Theoretical Particle and Energy Flux Formulas for Tokamaks," Comments Plasma Phys. Controlled Fusion 11 (1988) 165.

[8] J. Sheffield, "Tokamak Transport in the Presence of Multiple Mechanisms," Sherwood Controlled Fusion Theory Conference, Gatlinburg, TN, April 18-28, Abstract 1C35 (1988).

[9] C. S. Chang and F. L. Hinton, Phys. Fluids 29 (1986) 3314.

[10] C. E. Singer, D. E. Post, D. R. Mikkelsen, M. H. Redi, A. McKenney et al., Computer Phys. Communicationg 49 (1988) 275.

[11] C. E. Singer, M. H. Redi, D. A. Boyd, A. J. Cavallo, B. Grek, et al., Nuclear Fusion 25 (1985) 1555.

[12] W. Tang, G. Rewoldt, C. Cheng, and $\backslash$. Chance, Nucl. Fusion 25 (1985) 151 .

[13] W. Tang, G. Rewoldt, and L. Chen, Phys. Fluids 29 (1986) 3715. 
[14] G. Rewoldt, W. M. Tang, and R. J. Hastie, Phys. Fluids 30 (1987) 807.

[15] D. W. Ross, P. H. Diamond, J. F. Drake, F. L. Hinton, F. W. Perkins, W. M. Tang, R. E. Waltz, and S. J. Zweben, "Thermal and Particle Transport for Ignition Studies," DOE/ET-53193-7 and University of Texas Fusion Research Center Report FRCR \# 295 (1987).

[16] B. A. Carreras, P. H. Diamond, M. Murakami, J. L. Dunlap, J. D. Bell, H. R. Hicks, J. A. Holmes, E. A. Lazarus, V. K. Paré, P. Similon, C. E. Thomas, and R. M. Wieland, Phys. Rev. Lett. 50 (1983) 503.

[17] P. H. Diamond and B. A. Carreras, Comments Plasma Phys. Controlled Fusion 10 (1987) 279.

[18] B. A. Carreras, L. Garcia, and P. H. Diamond, Oak Ridge National Laboratory Report ORNL/TM-10150 (1980).

[19] W. Horton, "Drift Wave Turbulence and Anomalous Transport," Handbook of Plasma Physics, Eds. M. N. Rosenbluth and D. Z. Sagdeev, Vol. 2, Basic Plasma Physics II (Elsevier, NY, 1984).

[20] W. H. Choe and J. P. Freidberg, Phys. Fluids 29 (1986) 1768.

[21] C. E. Singer, G. Bateman, and D. P. Stotler, "Boundary Conditions for $\mathrm{OH}, \mathrm{L}$, and H-Mode Simulations," Princeton Plasma Physics Laboratory Report PPPL-2527 (1988).

[22] C. E. Singer, J. Fusion Energy 1 (1983) 231.

[23] S. M. Kaye and R. J. Goldston, Nucl. Fusion 25 (1985) 65.

[24] S. M. Kaye, ITER International Tokamak Reactor Internal Report, (May, 1988).

[25] K. Lackner, O. Gruber, and K. Grassie, "Different Confinement Regimes in Tokamaks," in Theory of Fusion Plasmas eds. A. Bodeson, E. Sindoni, and F. Troyon, Società Italian di Fisica (1988) p. 377.

[26] C. E. Singer and T. Djemil, "Maximum Likelihood Estimators for Tokamak Confinement Models" University of Illinois at Urbana-Champaign Fusion Studies Laboratory Rep. FSL-242 (1988). 
Table 1. Formulas, mostly from Ross et al.

Symbol Name (units) Formula

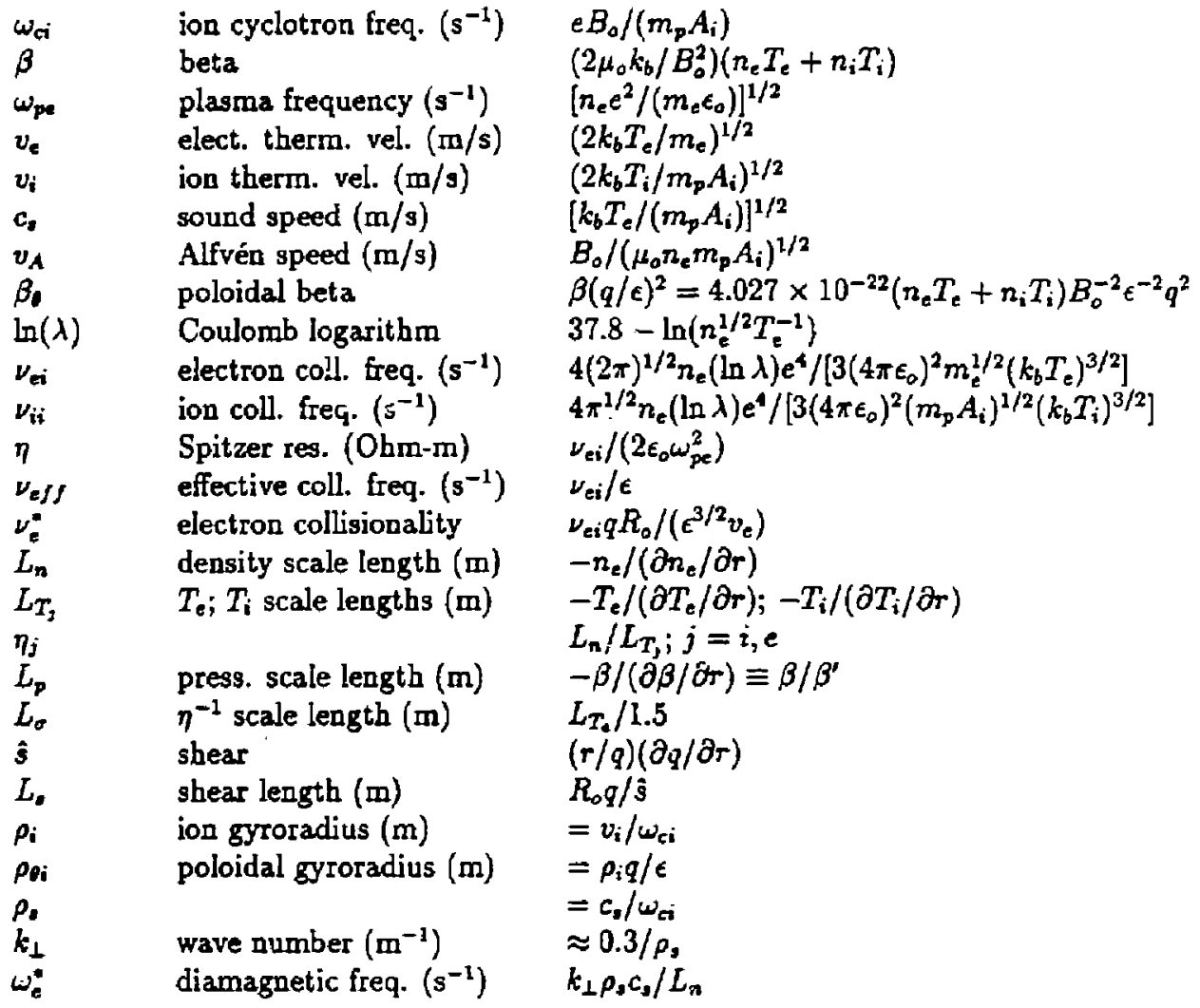


Table 2. L-Mode Confinement Scaling Exponents

\begin{tabular}{cccccc} 
Parameter & \multicolumn{2}{c}{ Simulations } & \multicolumn{3}{c}{ DataFits } \\
& Nominal & Improved & Singer & K-G & Kaye \\
& & & & & \\
$I$ & 0.7 & 0.8 & 1.1 & 1.2 & 0.85 \\
$B$ & 0.6 & 0.5 & -0.1 & -0.1 & 0.3 \\
$P$ & .0 .5 & -0.6 & -0.5 & -0.6 & -0.5 \\
$\bar{n}_{e}$ & 0.3 & 0.2 & 0.1 & 0.3 & 0.1
\end{tabular}




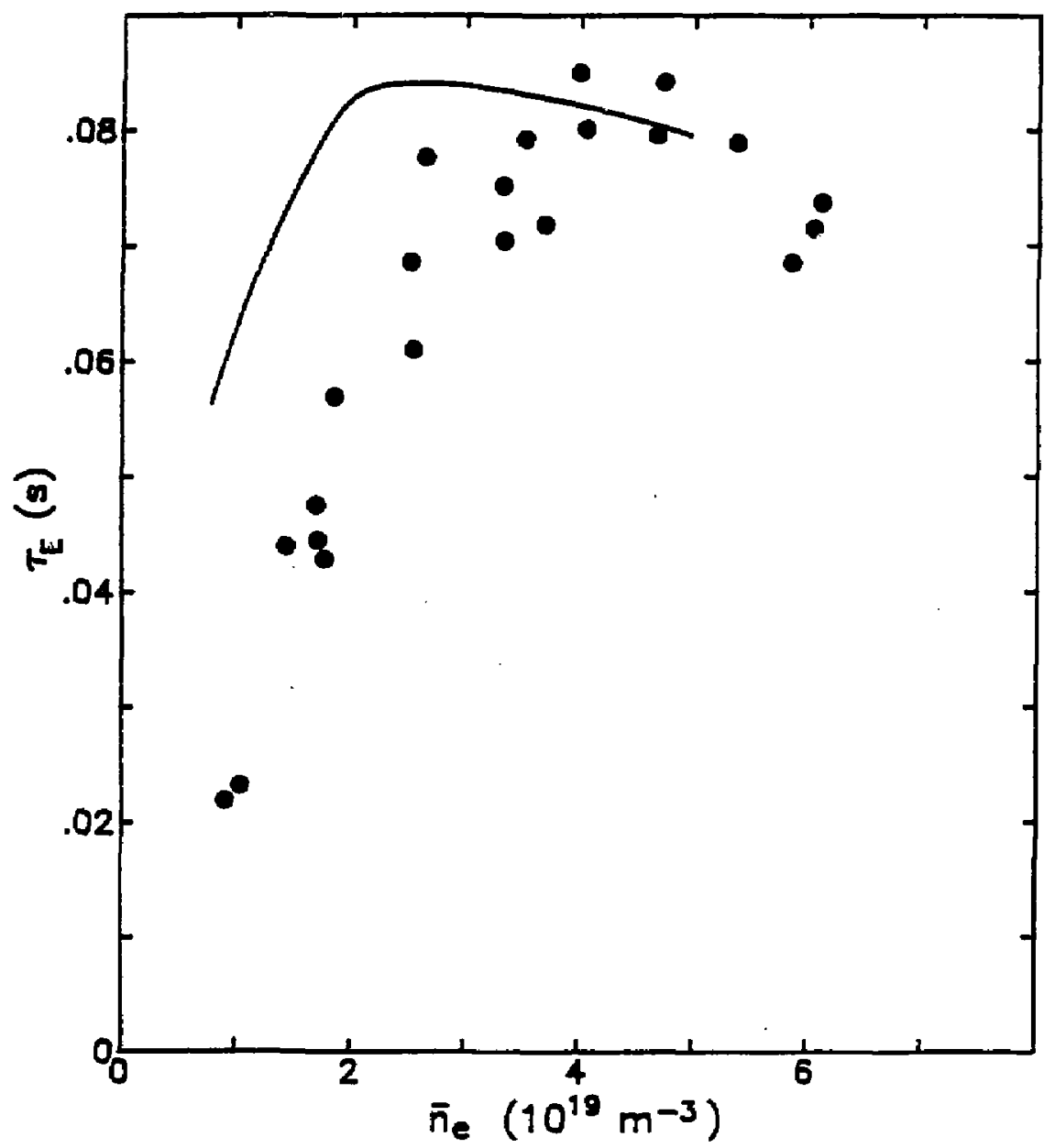

Fig. 1. Global energy confinement time for "improved" model described in the text (with $c_{1}=0.3, c_{2}=3$, and $c_{3}=1$; solid curve) vs. experimental data from ASDEX. 
Dr. Frank J, Peoloni, Univ of Wollongong, AUSTRALIA

Prof. M.H. Brannan, Univ Sydnoy, Australia

Plasac Rasaorch Leb., Austral ian Not. Univ., AUSTRALIA

Prof, I.R. Jones, Flinders Univ, , Australia

Prof. F. Cap, Inst Theo Pirs, MustRiA

Prof. M. HeIndier, Instut fur Theoretische Physik, AUSTRIA

M. Coosens, Astronomisech Instituut, BeLGIUN

Ecole Royale militalre, La de Phys Pleseas, Belgiun

Comission-Europan, Dg-XII Fusion Prog. BELGILA

Prof. R. Bouclaue, RI jksun lversitolt Gent, BELGIUN

Dr. P.H. Sakenake, Instituto Fisica, BRazIL

Instituto De Pasquisas Especiesi-IRPE, BRAz $1 L$

Docuents offles, Ateale Energy of Cened Limited, Cuwach

De. M.P. Bechynski, wo Technologles, Inc., cewuph

Dr. H.M. Sucragerd, Uniwersity of Sakketchewan, Cawan

Dr. H. Bernare, University of Britlah Columbie, Cuwan

Prof. J. Toichmann, Univ, of montrasi, Cawon

Prof. S.R. Sremivasen, Lniversity of Colgary, CMmon

Prof. Tucor W. Johnston, INestenergie, chwok

Dr. Bolton, Centre cenedien fulion agnetique, chuba

Dr. C.R. Jeme. Univ, of Alberta, Cunon

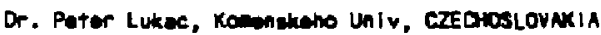

The Librerien, Culthe Leboratory, Ekelano

The Librerien, Ruthertord Appleton Laboratory, EkelNO

Hrs. S.A. Hutehinson, JET Library, EkCLAND

C. Houttet, Leb. De Phylawe doe Mllieux lonises, FRuce

J. Rader, CENJCADARAGE - Bat 506, FRAMCE

4s. C. Rimi, Librerien, Utiv. of loennina, EAEECE

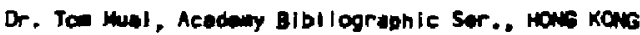

Preprint Librery, Hungerien Mendery of Sciences, Hivahay

Dr. 8. Das Gupta, Sene inst of Hucl. Phys., INOIA

Or. P. Kan, Instlitute for Plasen Reseoreh, INDIA

Dr. Philip Rosenas, I grael inst. of Tech, ISRAEL

Librerien, Int'l Ctr Theo Phys, ITALY

Prof. 6. Rostegni, istituto Gas Ionizzati Del OA, ITALY

Miss Clelis Do Pelo, Aseoc ELRATOn-EMEA, ITALY

Dr. G. Grosso, Istituto di fisica de PIasea, ITALY

Dr. H. Yemaro, Toshibe Ras \& Dev, JAPAM
Prof. 1. Kanakaai, Atonic Enorgy Ras. Institute, JAPAN

Prof. Kroji Nishikama, Univ of Hiroshime, JAPAN

Director, Dapt. Larga Tokamak Ras. JAERI, JAPAN

Prof. Satoshi Itoh, Kyushu Univarsity, JAPAN

Ressearch Into Centar, Negora University, JAPAN

Prof. S. Tanake, Kyoto University, JdPAN

Library, Kyoto University, JAPAN

Prof. Nobuyuki Inowe. University of Tokyo, JAPAN

S. MOC I, JAERI, JAPAK

H. Jeong, LIbrerien, Korea Advanced Energy Ros Inst, KOAEA

Prot. D.1. Chol, The Kores Adv. Inst of Sel t Teen, KOREA

Prot. 8.5. Liley, University of Moiketo, HEW ZEALANo

institute of Plase Physics, PEOPLE's Repuadic of CHIM

Librarian. Institute of Phys., PEOPLE's REPUBL IC Of CHIMA

Library, Tsing the University, PEOPLE's REPUALIC of CHIMA

Z. Li, Southwent Inst. Physies, PEOPLE's PEPUBLIC of CMINA Prof. J.A.C. Cabral, Inst Superior Teenico, RoRTugal.

Dr. Octavian Petrus, AL I CJZA Univorsity. Rounia

Or. Jen de villiars, Fusion Studies, AEC, SO AFRICA

Prof. M.A. Hellberg, University of Matal, SO AFRICA

C.I.E.H,A.T., Fusion Div. Library, SPAIN

Dr. Lennart Stenflo, University of UEEA, SWEDEN

Librery, Boyol Institute of Tech, SHEDEN

Prot. Hans Withelmeon, Chalwers Unir of Tech, SwEDEN

Cantra Phys des PIasuas, Ecole Polytech fod, SWITZEPLANO

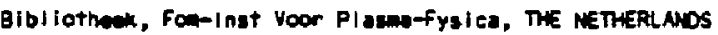

Wat in Durgut, Middle East Technicel University, TuRerey

Dr. O.D. Ryutor, Siberian Aced Scl, USSR

Dr. G.A. El isaew, Kurchator institute, USSR

Or. V.A. Glukhikh, Inst Eloctrophysleal Apparatus, USSR

Prof. 0,5. Padichenko, Inst, of Phys, a Tech. USSR

Dr. L.H. Kovrizhnykh, Institute of Gan. Physies, USSR

Nuclater Ros. Estoblishaent, Julich Ltd., W. GERMaNY

Bibliathek, Inst. Fur Plasmeforschung, W. GefunwY

Dr, K. Schindler, Ruhr-Univers itat Eochum, H. GERANY

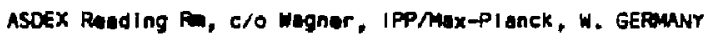
Librarian, Max-Plauck Institut, W. Gerowaky

Prof. R.K. Jenev, Inst of Phys, Yucoslavia

\section{REPRODUCED FROM BEST AVALABLE COPY}

